\title{
DONRYU, Rat Strain
}

National Cancer Institute

\section{Source}

National Cancer Institute. DONRYU, Rat Strain. NCI Thesaurus. Code C14399.

DONRYU: Spontaneous tumors $74 \%$ in males at 120 -weeks, mostly pituitary adenomas,

pheochromocytomas and insulinomas. In females incidence $89 \%$, mostly uterine adenocarcinomas, mammary fibroadenomas and pituitary adenomas. 